\title{
Oxyalkylation of condensed tannins with propylene carbonate as an alternative to propylene oxide
}

\author{
Antoine Duval, Luc Avérous* \\ Bioteam/ICPEES-ECPM, UMR CNRS 7515, \\ Université de Strasbourg, 25 rue Becquerel, 67087 Strasbourg Cedex 2, France \\ * Corresponding author: Prof. Luc Avérous, Phone: + 333 68852784, Fax: + 333 68852716, \\ E-mail: luc.averous@unistra.fr
}

\section{Supporting information}

19 pages

1 Table

24 Figures 
Table S1. Quantification of OH groups in MT, according to the integration boundaries given by Melone et al. ${ }^{1,2}$

\begin{tabular}{l|c|c} 
Functional group & $\begin{array}{c}\text { Integration } \\
\text { range }(\mathbf{p p m})\end{array}$ & $\begin{array}{c}\text { Amount } \\
\left(\mathbf{m m o l . g} \mathbf{- 1}^{\mathbf{1}}\right)\end{array}$ \\
\hline Aliphatic $\mathrm{OH}$ & $149-145.2$ & 4.9 \\
$o$-disubstituted phenols & $143.5-141.5$ & 1.7 \\
catechols & $140.5-138.3$ & 3.3 \\
noncatecholic $o$-substituted phenols & $138.3-137.8$ & 1.0 \\
$o$-unsubstituted phenols & $137.8-136.5$ & 1.6 \\
$\mathrm{COOH}$ & $135.5-134.0$ & $n d$ \\
\hline Total phenols & & 7.7 \\
Total OH & & 12.6
\end{tabular}




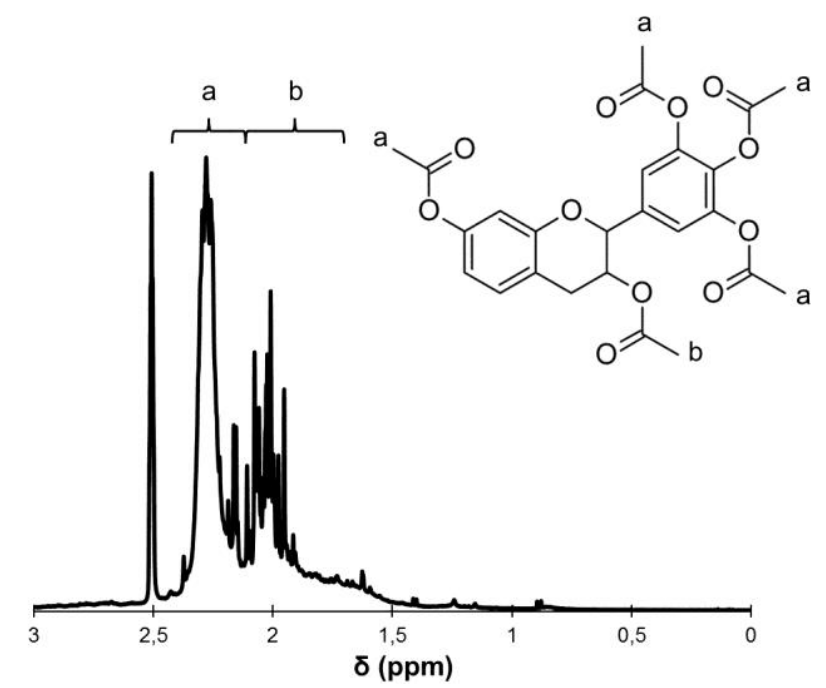

Figure S1. ${ }^{1}$ H NMR spectrum of Acacia mearnsii tannins (MT), after acetylation to quantify the content in $\mathrm{OH}$ groups. Assignation is given for a prorobinetinidin unit, see the text for more details.

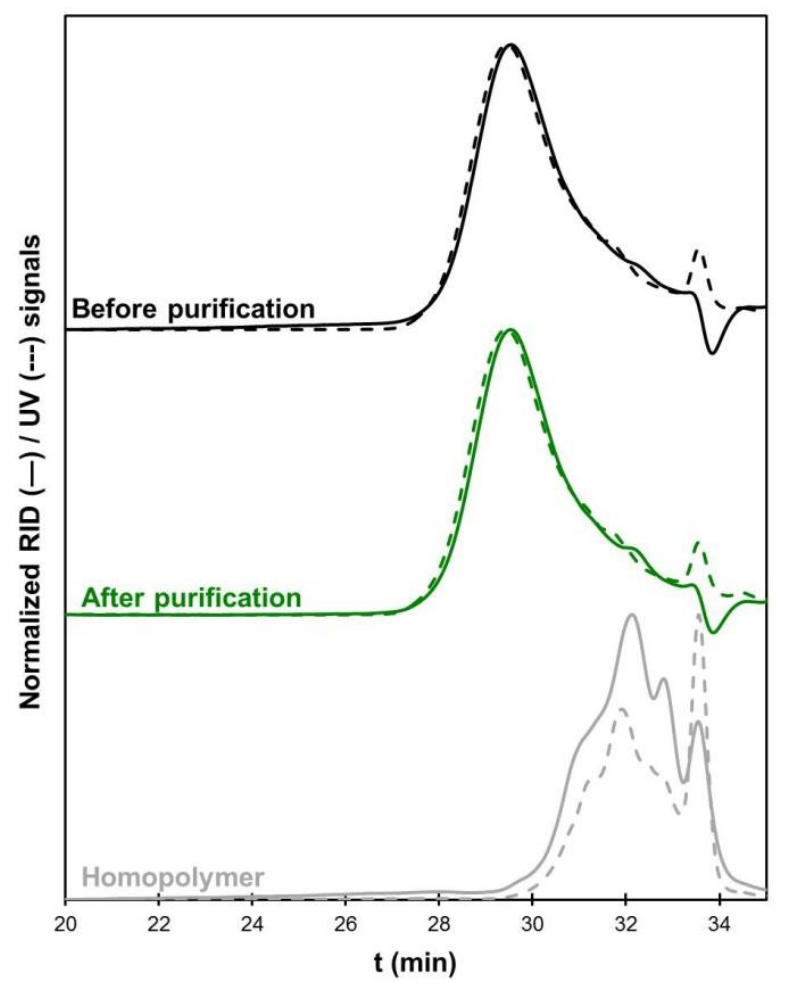

Figure S2. SEC of MT oxypropylated with 2 equivalents of PO, measured by RID (continuous line) and UV detection (dashed line): before purification (top curves), after purification (middle curves) and homopolymer fraction (bottom curves). 


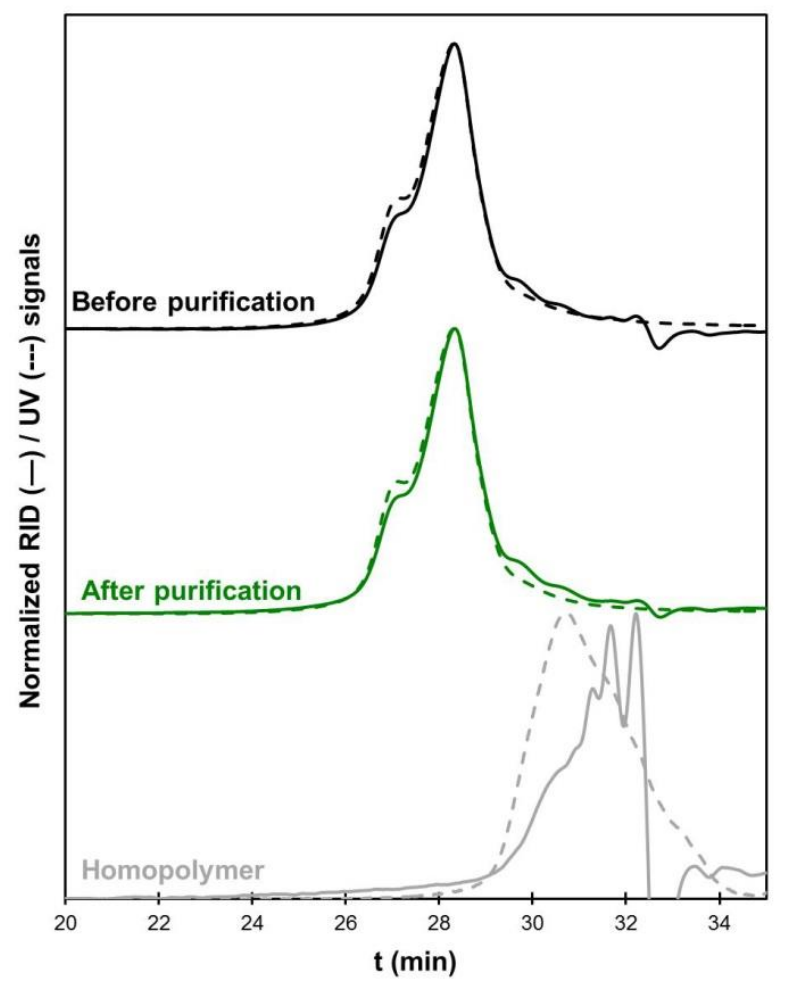

Figure S3. SEC of MT oxypropylated with 4 equivalents of PO, measured by RID (continuous line) and UV detection (dashed line): before purification (top curves), after purification (middle curves) and homopolymer fraction (bottom curves). 


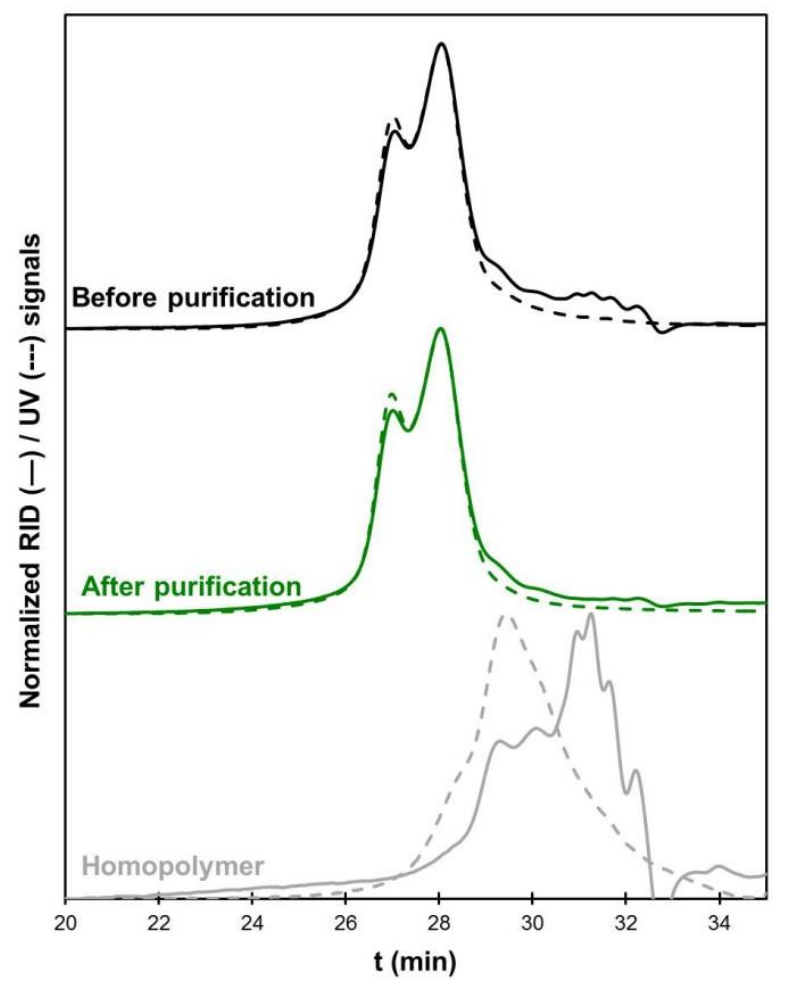

Figure S4. SEC of MT oxypropylated with 6 equivalents of PO, measured by RID (continuous line) and UV detection (dashed line): before purification (top curves), after purification (middle curves) and homopolymer fraction (bottom curves). 


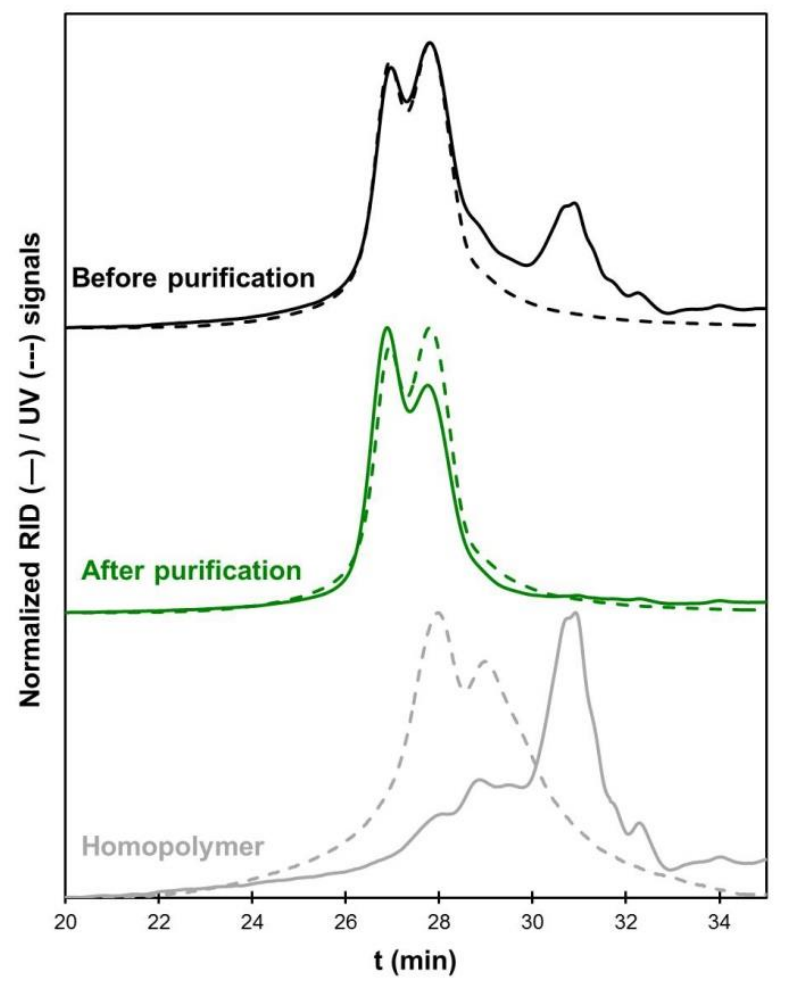

Figure S5. SEC of MT oxypropylated with 8 equivalents of PO, measured by RID (continuous line) and UV detection (dashed line): before purification (top curves), after purification (middle curves) and homopolymer fraction (bottom curves).

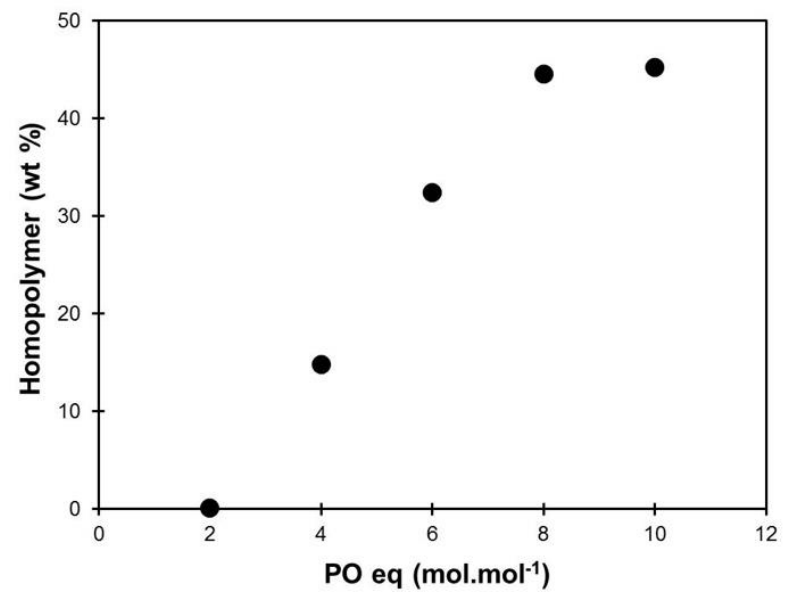

Figure S6. Yield of the homopolymer fraction extracted with cyclohexane, depending on the amount of PO used for the reaction. 


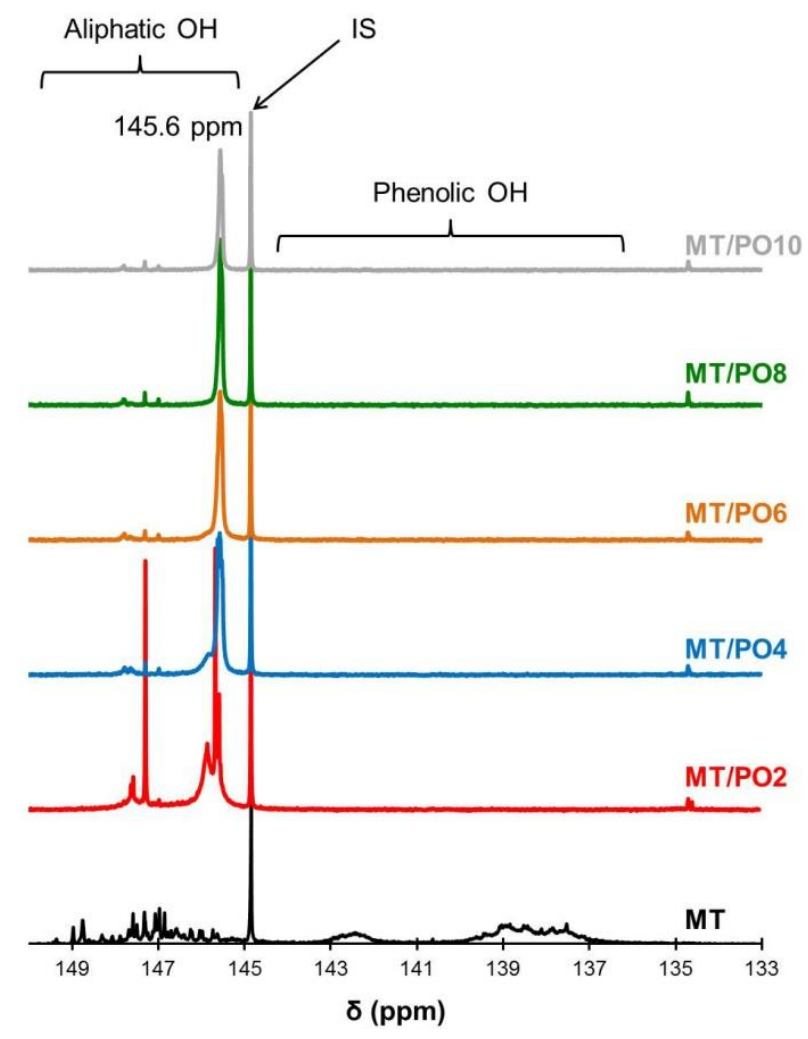

Figure S7. ${ }^{31} \mathrm{P}$ NMR spectra of the tannins oxypropylated with various amounts of PO. Samples derivatized with 2-chloro-4,4,5,5-tetramethyl-1,3,2-dioxaphospholane. IS = internal standard (cholesterol). 


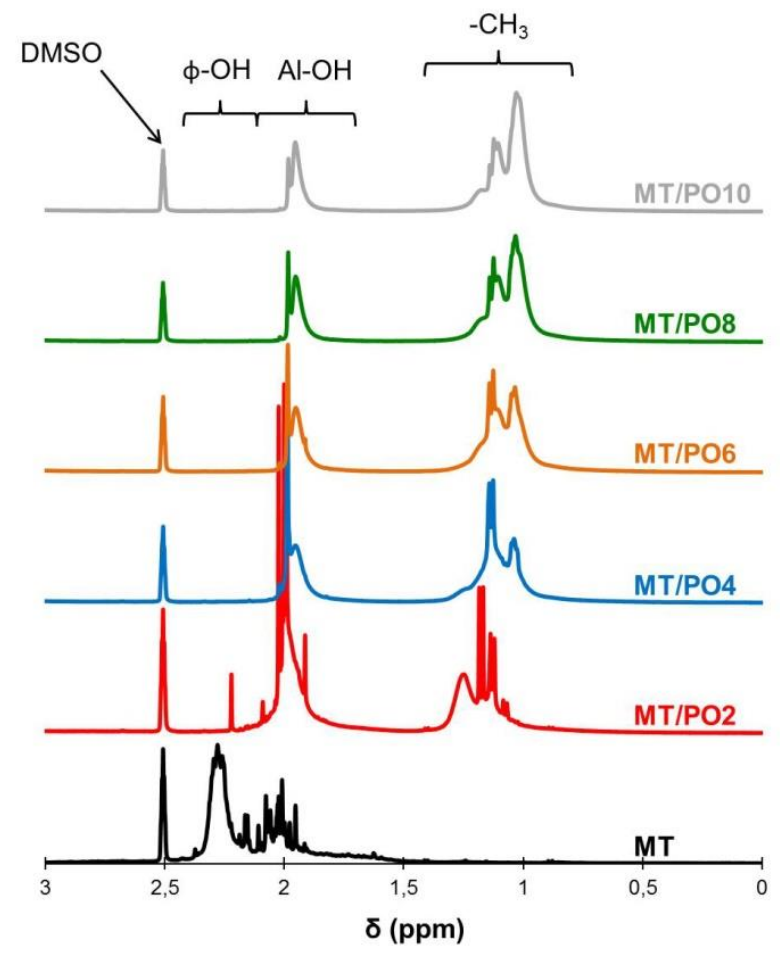

Figure S8. ${ }^{1} \mathrm{H}$ NMR spectra of the tannins oxypropylated with various amounts of PO, after acetylation. 


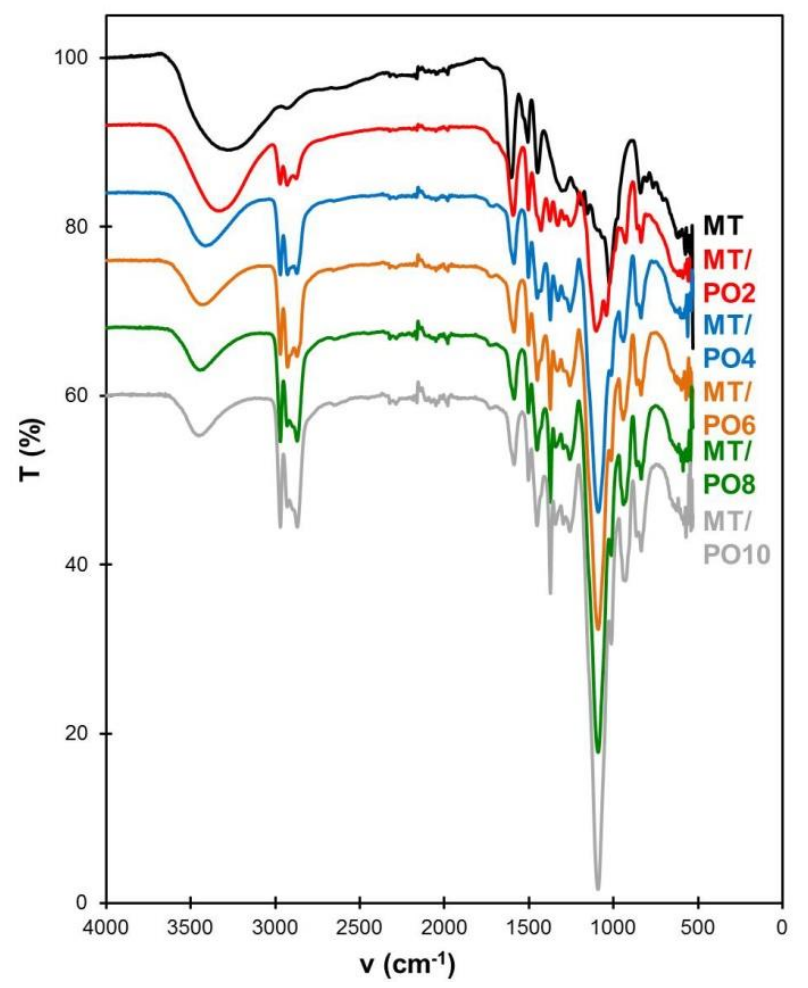

Figure S9. FTIR spectra of the tannins oxypropylated with various amounts of PO.

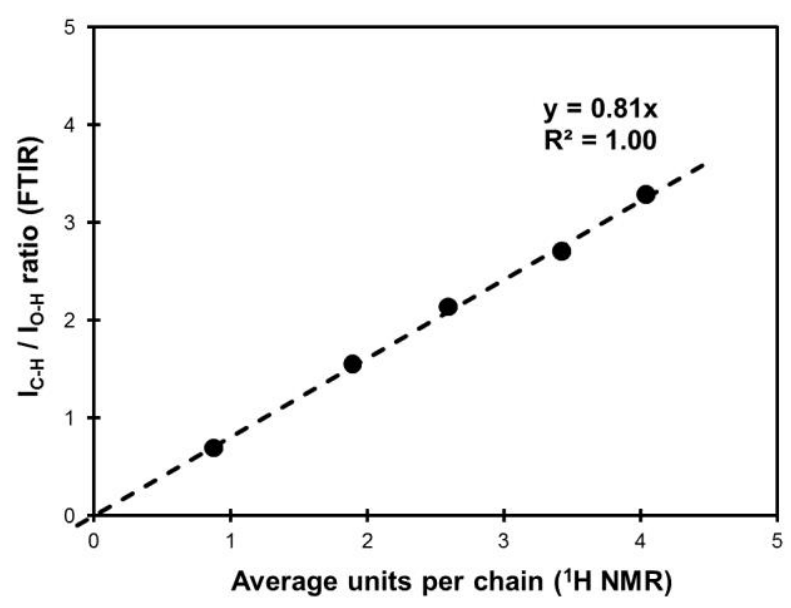

Figure S10. Relationship between the ratio of FTIR peak intensities $\mathrm{I}_{\mathrm{C}-\mathrm{H}} / \mathrm{I}_{\mathrm{O}-\mathrm{H}}$ and the average length of the polyether chain measured by ${ }^{1} \mathrm{H}$ NMR 


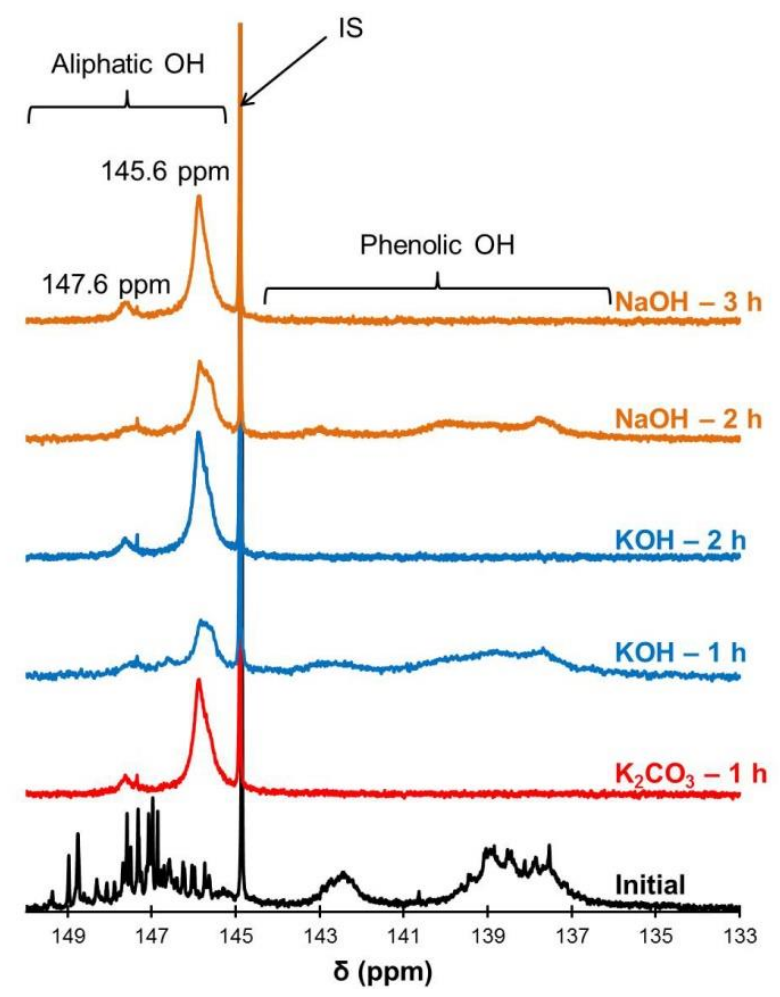

Figure S11. ${ }^{31} \mathrm{P}$ NMR spectra of the tannins oxypropylated with PC for various reaction times $\left(10\right.$ eq $\left.\mathrm{PC}, 170{ }^{\circ} \mathrm{C}\right)$, depending on the catalyst used. 

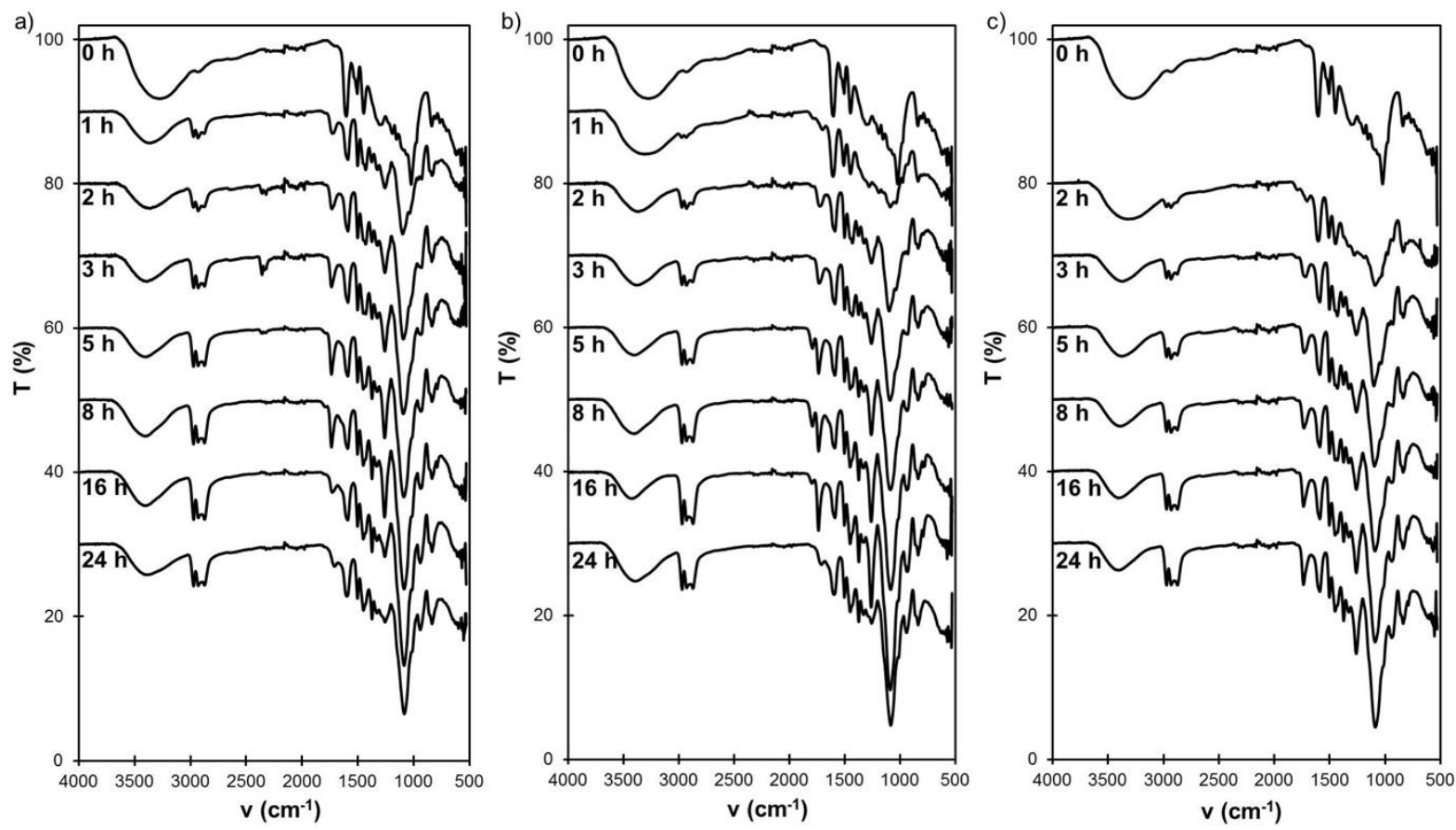

Figure S12. FTIR spectra of the tannins oxypropylated with PC $\left(10 \mathrm{eq}, 170{ }^{\circ} \mathrm{C}\right)$, depending on the reaction time, for different catalysts: (a) $\mathrm{K}_{2} \mathrm{CO}_{3}$, (b) $\mathrm{KOH}$, (c) $\mathrm{NaOH}$. 


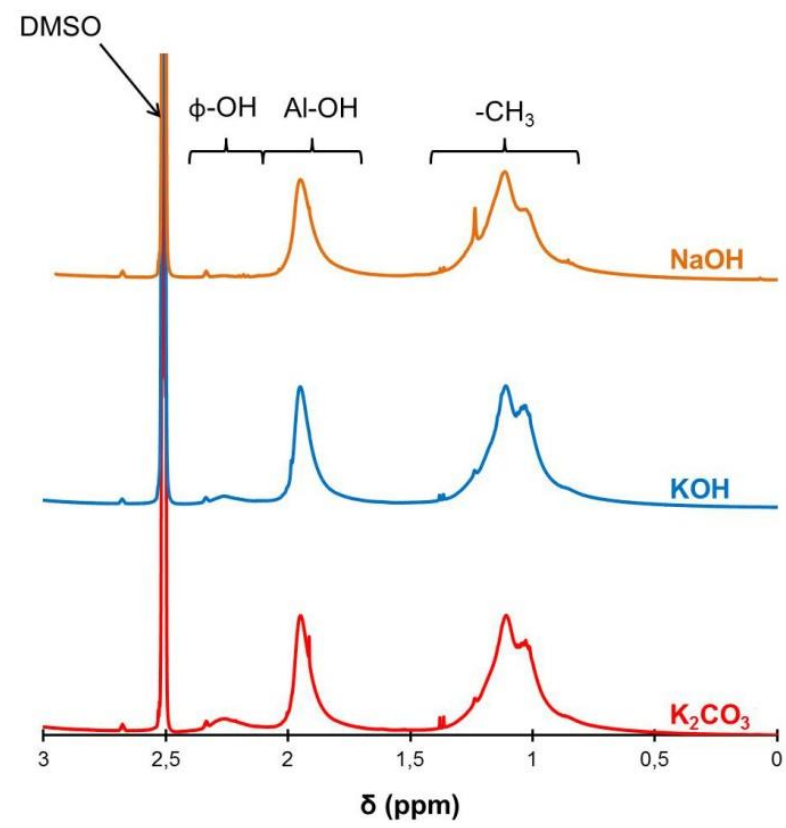

Figure S13. ${ }^{1} \mathrm{H}$ NMR spectra of the tannins modified with PC $\left(10 \mathrm{eq}, 170{ }^{\circ} \mathrm{C}, 24 \mathrm{~h}\right.$ reaction $)$ and various catalysts after acetylation. 


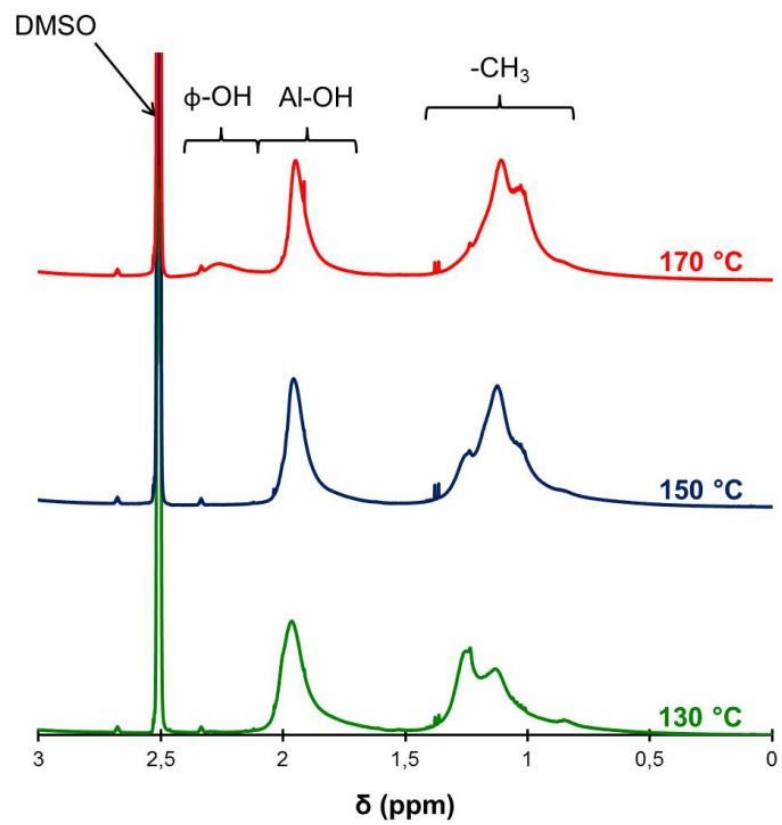

Figure S14. ${ }^{1} \mathrm{H}$ NMR spectra of the tannins modified with $\mathrm{PC}\left(\mathrm{K}_{2} \mathrm{CO}_{3}\right.$ as catalyst, 10 eq $\mathrm{PC}$, $24 \mathrm{~h}$ reaction), depending on the temperature, after acetylation.

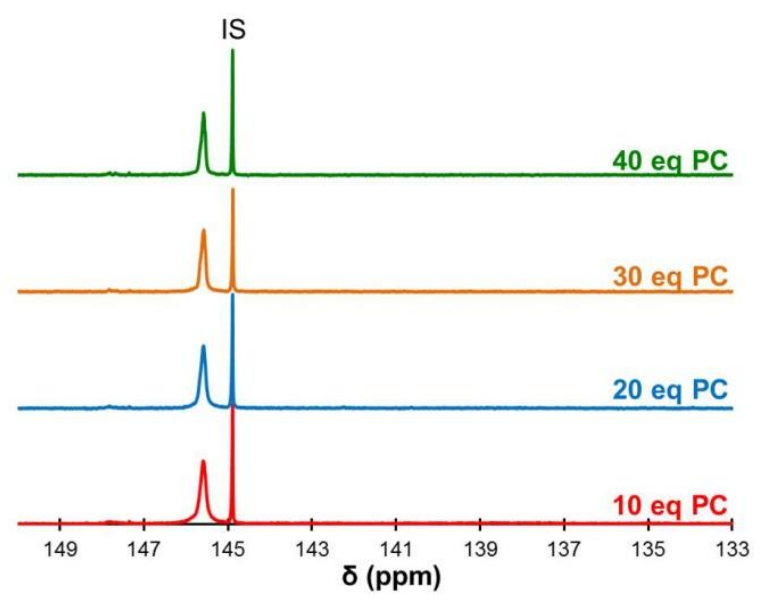

Figure S15. ${ }^{31} \mathrm{P}$ NMR spectra of the tannins modified with various amounts of $\mathrm{PC}\left(\mathrm{K}_{2} \mathrm{CO}_{3}\right.$ as catalyst, $24 \mathrm{~h}$ reaction at $\left.170{ }^{\circ} \mathrm{C}\right)$. 


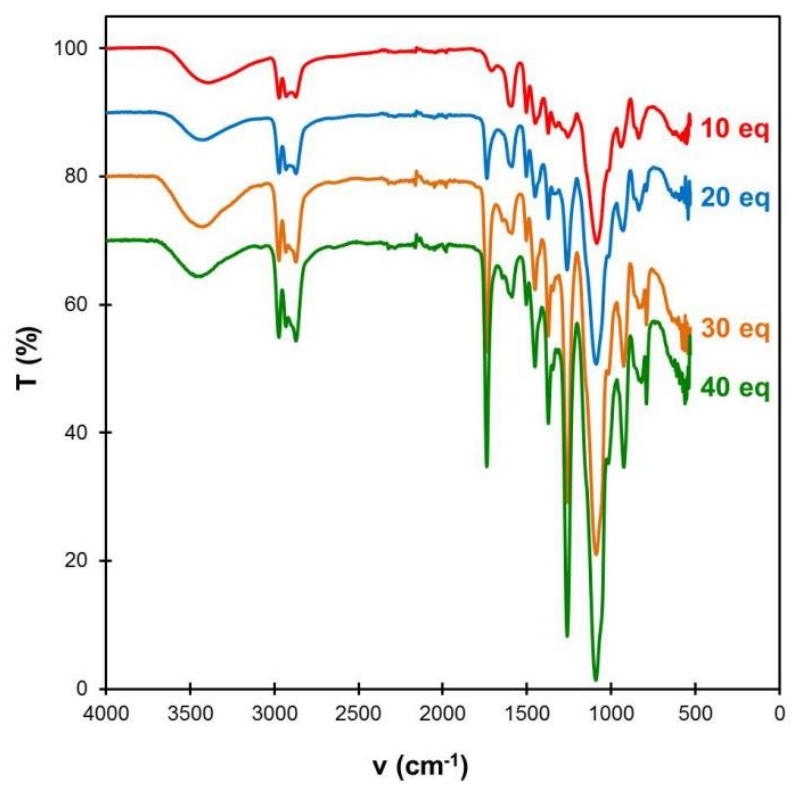

Figure S16. FTIR spectra of the tannins oxypropylated with various amounts of $\mathrm{PC}\left(\mathrm{K}_{2} \mathrm{CO}_{3}\right.$ as catalyst, $24 \mathrm{~h}$ reaction at $170{ }^{\circ} \mathrm{C}$ ) 


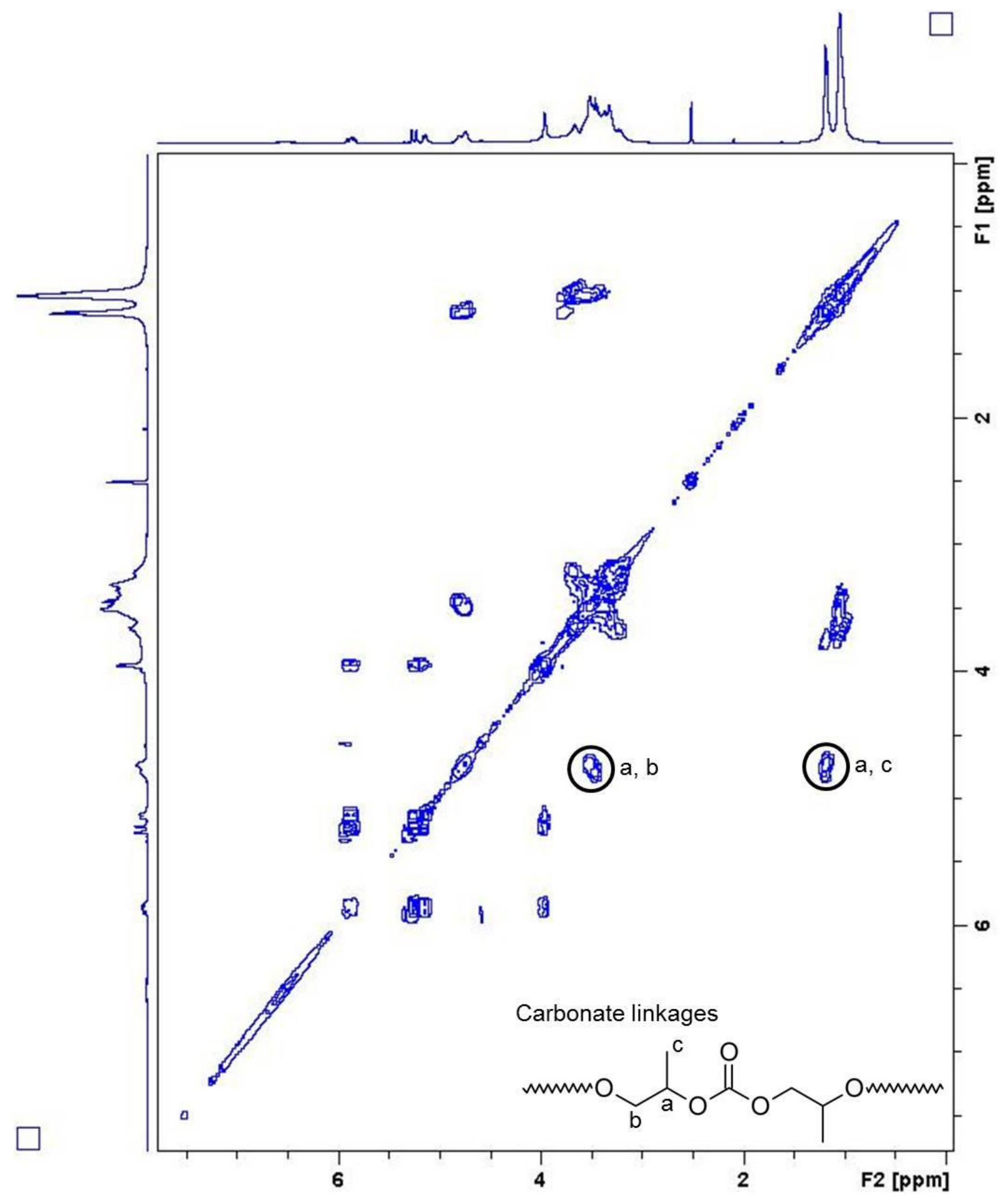

Figure S17. COSY NMR spectrum of tannin modified with 40 eq PC 


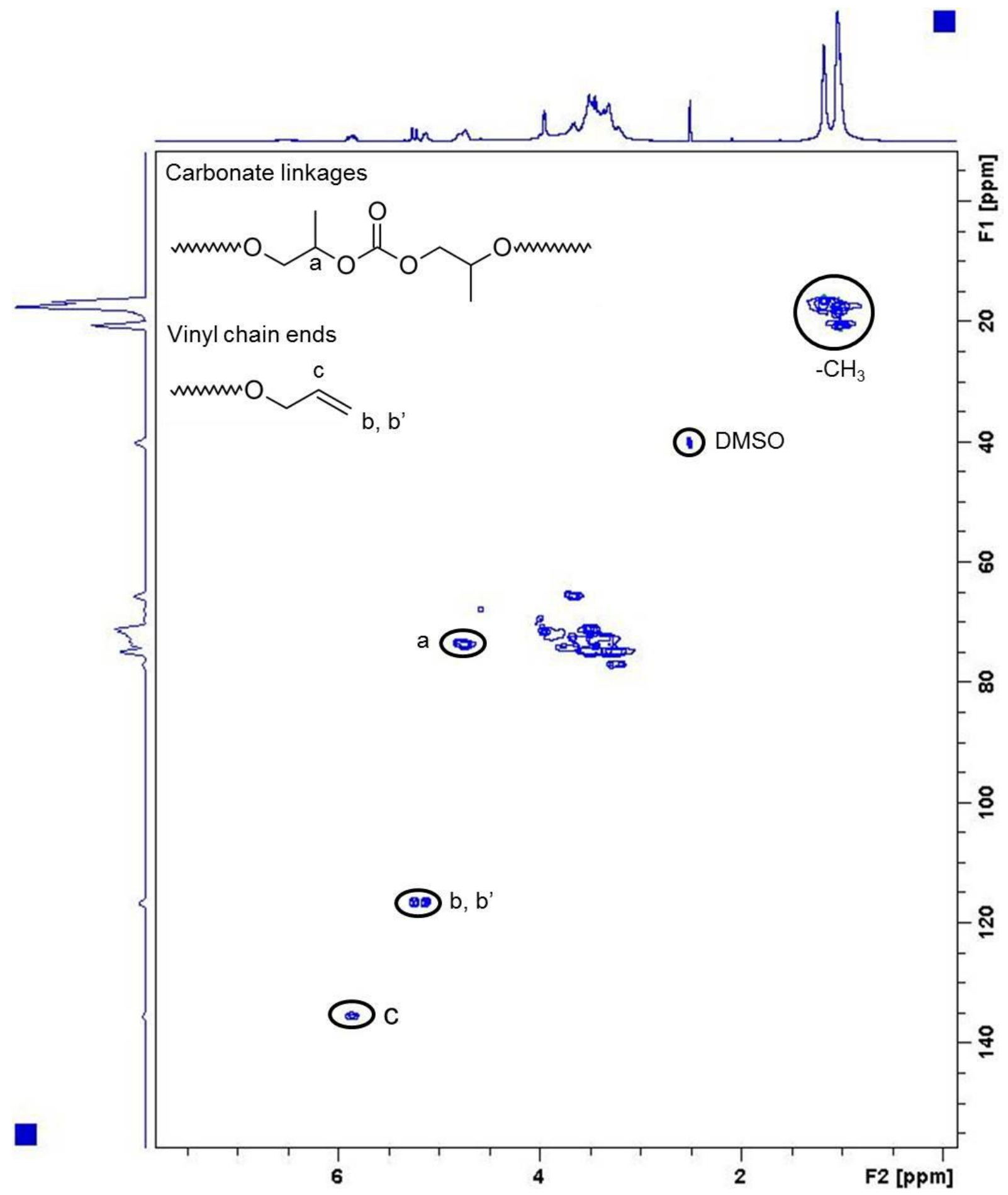

Figure S18. HSQC NMR spectrum of tannin modified with 40 eq PC 


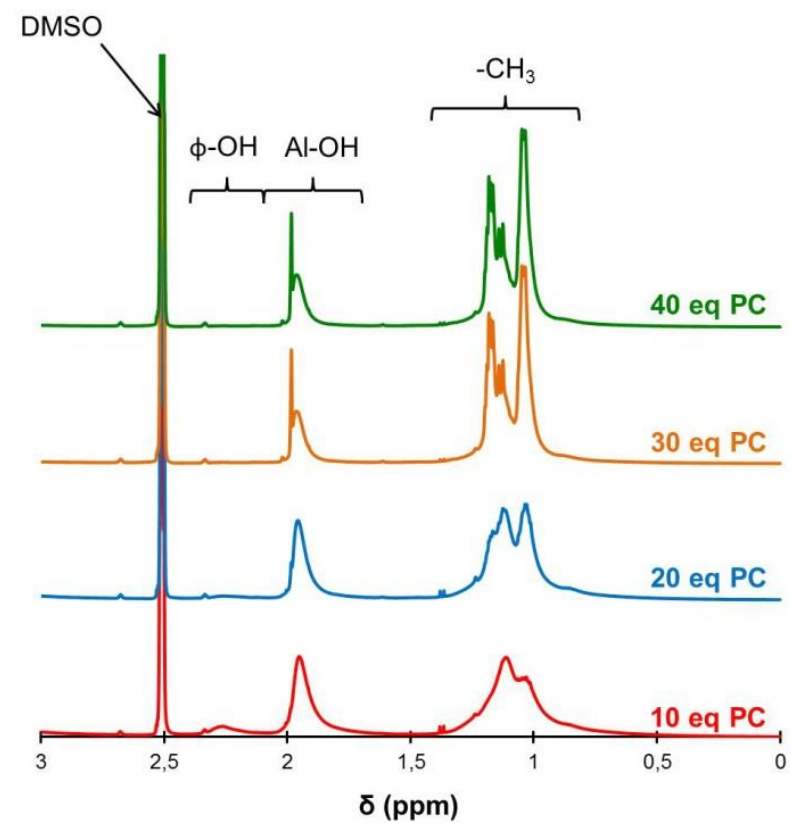

Figure S19. ${ }^{1} \mathrm{H}$ NMR spectra of the tannins modified with various amounts of $\mathrm{PC}\left(\mathrm{K}_{2} \mathrm{CO}_{3}\right.$ as catalyst, $24 \mathrm{~h}$ reaction at $\left.170{ }^{\circ} \mathrm{C}\right)$, after acetylation.

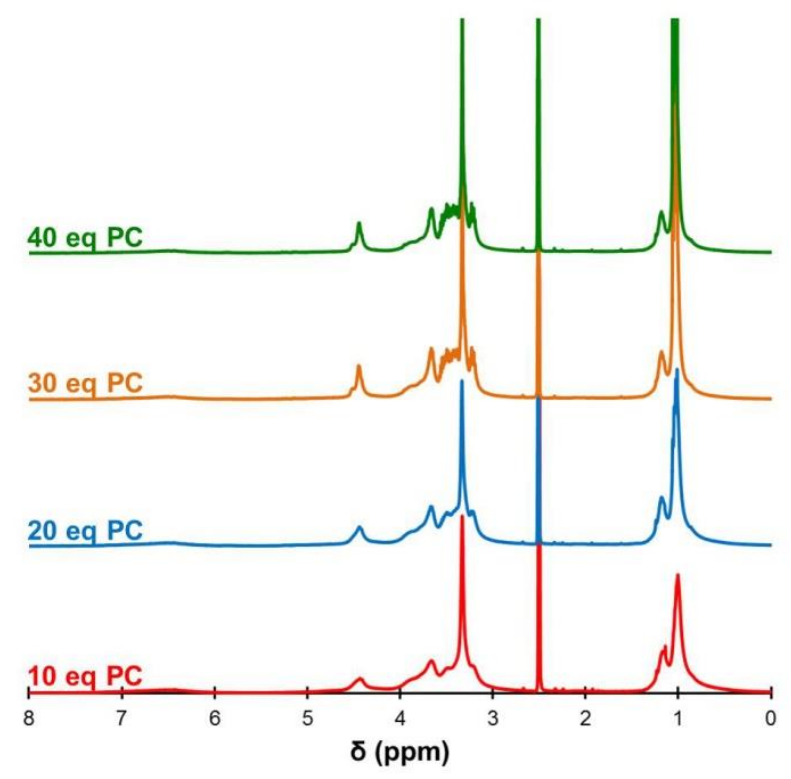

Figure S20. ${ }^{1} \mathrm{H}$ NMR spectra of the tannins modified with various amounts of $\mathrm{PC}\left(\mathrm{K}_{2} \mathrm{CO}_{3}\right.$ as catalyst, $24 \mathrm{~h}$ reaction at $170{ }^{\circ} \mathrm{C}$ ), after hydrolysis of the carbonate linkages 


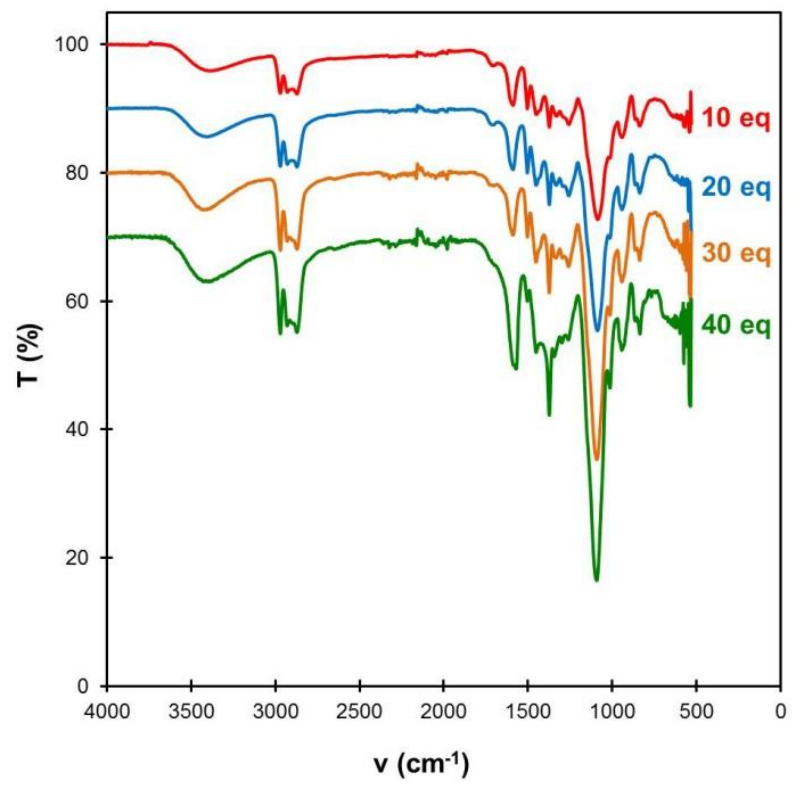

Figure S21. FTIR spectra of the tannins modified with various amounts of $\mathrm{PC}\left(\mathrm{K}_{2} \mathrm{CO}_{3}\right.$ as catalyst, $24 \mathrm{~h}$ reaction at $170{ }^{\circ} \mathrm{C}$ ), after hydrolysis of the carbonate linkages

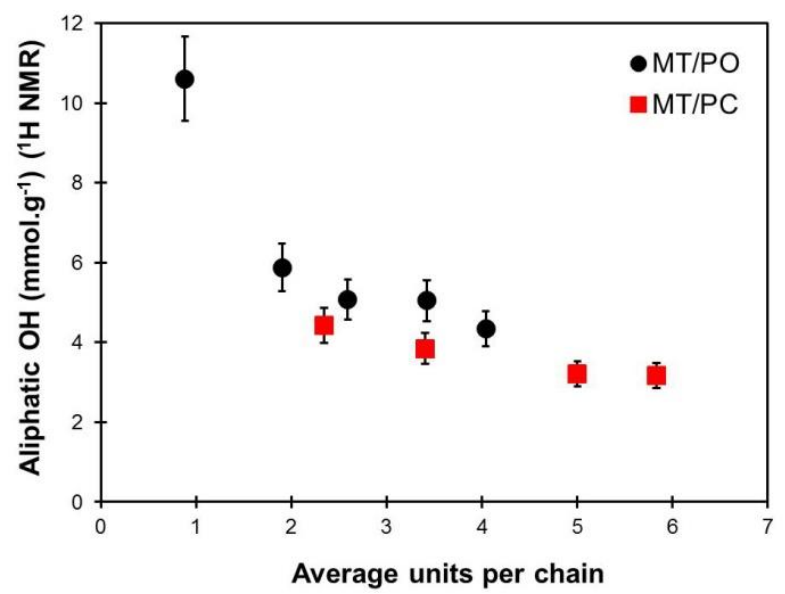

Figure S22. OH content (measured by ${ }^{1} \mathrm{H}$ NMR) of the tannins oxypropylated with PO and PC, depending on the average length of the grafted chain. 


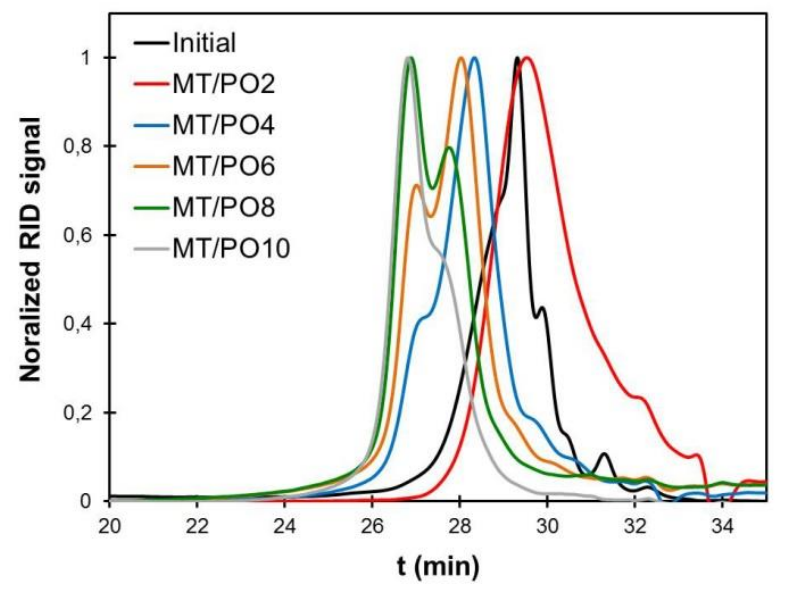

Figure S23. Size exclusion chromatograms of tannins oxypropylated with various amounts of PO

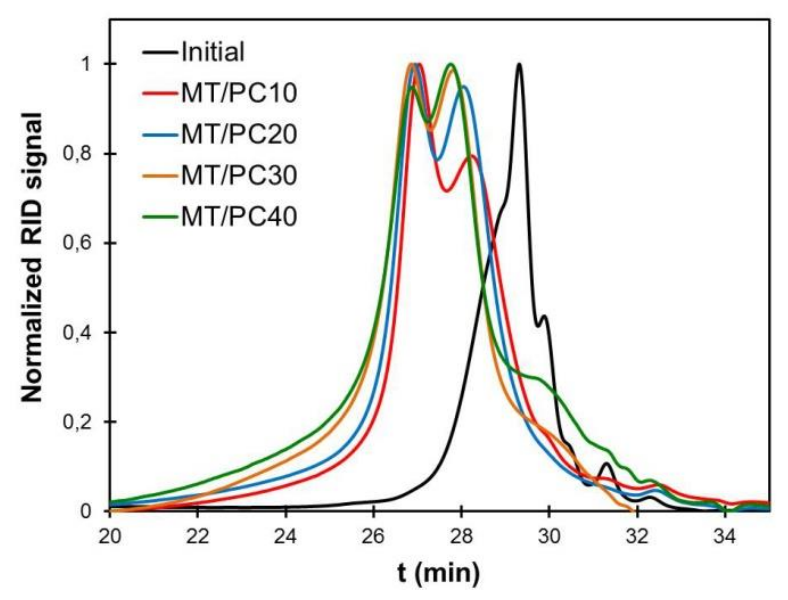

Figure S24. Size exclusion chromatograms of tannins oxypropylated with various amounts of PC

\section{References}

(1) Melone, F.; Saladino, R.; Lange, H.; Crestini, C. Tannin Structural Elucidation and Quantitative 31P NMR Analysis. 1. Model Compounds. J. Agric. Food Chem. 2013, 61 (39), 9307-9315.

(2) Melone, F.; Saladino, R.; Lange, H.; Crestini, C. Tannin Structural Elucidation and Quantitative 31P NMR Analysis. 2. Hydrolyzable Tannins and Proanthocyanidins. $J$. Agric. Food Chem. 2013, 61 (39), 9316-9324. 